\title{
A PLENA DELIBERAÇÃO INTERNA DO SUPREMO TRIBUNAL FEDERAL PARA A EFETIVA CRIAÇÃO DOS PRECEDENTES JUDICIAIS VINCULANTES ESTABELECIDOS PELO NOVO CÓDIGO DE PROCESSO CIVIL
}

THE FULL INTERNAL DELIBERATION OF THE FEDERAL SUPREME COURT FOR THE EFFECTIVE CREATION OF THE BINDING JUDICIAL PRECEDENTS ESTABLISHED BY THE NEW CIVIL PROCEDURE CODE

Peter Panutto

\section{Resumo}

O artigo trata da implantação pelo Novo Código de Processo Civil brasileiro de um sistema de precedentes judiciais vinculantes e da consequente necessidade de adequação dos procedimentos de votação colegiada do Supremo Tribunal Federal e dos demais tribunais de nosso país, para que as decisões geradoras de precedentes sejam resultado de plena deliberação colegiada, com reconhecimento institucional do precedente. São analisados os modelos de decisão colegiada seriatim, per curiam e majoritarian practice, concluindo-se que este último é mais apropriado aos tribunais brasileiros. 0 objetivo do artigo é demonstrar que a não adequação do procedimento deliberativo dos tribunais acarretará a ineficácia desse sistema de precedentes. 0 método adotado é hipotético-dedutivo, mediante análise crítica da necessidade de aprimoramento de criação e respeito dos precedentes.

Palavras-chaves: Deliberação colegiada. Novo Código de Processo Civil. Precedentes judiciais.

\section{Abstract}

the article deals with the implementation, as mandated y by the New Brazilian Civil Procedure Code, of a system of binding judicial precedents and 
the consequent need to adapt the collegiate voting procedures of the Federal Supreme Court and the others courts of our country so that the decisions generating precedents are the result of full collegial deliberation, with institutional recognition of the precedent. The models of collegiate decision seriatim, per curiam and majoritariam practice are analyzed, concluding that the latter is more appropriate to the Brazilian courts. The purpose of the article is to demonstrate that if the is not adapted to the aforementioned model, the deliberative procedure of the courts will result in inefficiency of this system of precedents. The method adopted is hypothetical-deductive, through a critical analysis of the need for improvement of the creation and respect of precedents.

Keywords: Collegial deliberation. Judicial precedents. New Code of Civil Procedure.

\section{INTRODUÇÃO}

A grande margem de interpretação de normas dispostas no ordenamento jurídico por meio de cláusulas abertas acarreta variação na forma de solução de conflito de causas semelhantes, o que gera instabilidade no sistema jurisdicional. Esta realidade é agravada pela atuação discricionária dos julgadores, os quais, via de regra, não se sentem parte de um sistema, de modo que a unidade jurisdicional é garantida apenas como Poder Judiciário, mas não como uniformização da atuação jurisdicional. Em regra, cada juiz se vê com autonomia para julgar o caso de acordo com a sua interpretação da lei, sem dever de obediência ao entendimento de seu tribunal superior ou de seu próprio tribunal.

Para além das decisões proferidas em controle concentrado de constitucionalidade, não havia, até o advento do Novo Código de Processo Civil, formas concretas de se buscar a uniformidade na interpretação da lei nas decisões judiciais, acarretando desrespeito aos princípios da isonomia, previsibilidade e segurança jurídica.

Esta crise sistêmica em nosso Poder Judiciário tende a ser resolvida com a implementação dos precedentes judiciais vinculantes constantes no Novo Código de Processo Civil, de modo a criar parâmetros para julgamento de matérias de direito, diminuindo-se em parte a margem de interpretação da lei. 
Contudo, a mera previsão legal de decisões geradoras de precedentes judiciais vinculantes não terá o condão de garantir a estabilidade nos entendimentos de nossos tribunais, caso não haja alteração no procedimento deliberativo para obtenção de decisões que efetivamente resultem em entendimento da Corte. Sem isto, a cada nova decisão, poderá ser gerado um novo precedente, com outro fundamento, sobre a mesma matéria de direito, a despeito de a decisão formalmente tipificar um dos incisos do art. 927 do Novo Código de Processo Civil.

Teremos, desta forma, a manutenção da instabilidade jurisprudencial tão presente em nosso sistema judiciário e a mera previsão legal, com pouca ou nenhuma eficácia, de precedentes judiciais vinculantes.

Visando contribuir com a efetiva implantação do sistema de precedentes judiciais vinculantes, será abordada a previsão legal deste instituto pelo Novo Código de Processo Civil, a realidade deliberativa do Supremo Tribunal Federal, bem como experiências deliberativas de outras Cortes Constitucionais em busca de plenos precedentes judiciais.

\section{OS PRECEDENTES JUDICIAIS VINCULANTES DO NCPC E A REALIDADE DELIBERATIVA DO STF}

O Novo Código de Processo Civil impõe um sistema de precedentes a ser adotado por todo o sistema judiciário nacional estabelecendo em seu art. $927^{1}$ que serão considerados precedentes vinculantes as decisões proferidas pelo Supremo Tribunal Federal geradoras de súmulas vinculantes e as proferidas em controle concentrado de constitucionalidade, as decisões proferidas pelo Supremo Tribunal Federal e pelo Superior Tribunal de Justiça geradoras de súmulas não vinculantes e proferidas em recursos extraordinários e especiais repetitivos, os acórdãos proferidos por qualquer tribunal em incidente de assunção de competência ou em resolução de demandas repetitivas, bem como a orientação do plenário ou do órgão especial de qualquer Tribunal.

Como não temos tradição na criação de precedentes, nossos tribunais apenas se atêm a julgar os recursos a eles dirigidos, proferindo acórdão que nega ou confere provimento ao apelo, preocupando-se 
apenas com a solução do caso concreto, sem qualquer visão prospectiva, não objetivando a criação de precedente para solução de casos correlatos futuros. Todavia, o correto seria que o tempo e recursos despendidos na solução do conflito individual também fossem aproveitados para paulatina formação de pauta de conduta (SANTOS, 2012, p. 189).

Contudo, para que os acórdãos proferidos pelos tribunais possam gerar precedentes, há necessidade de adequação do procedimento de votação em colegiado que permita a apresentação institucional dos resultados da deliberação, em um texto único, através do esgotamento dos argumentos relevantes do caso, de modo a permitir posterior identificação da ratio decidendi no julgado.

0 atual procedimento de julgamento dos recursos pelos tribunais, nos quais, cada magistrado, de modo unipessoal, com suas assessorias, e sem diálogo e contraditório pleno entre eles e com os advogados, “[...] proferem seus votos partindo de premissas próprias e construindo fundamentações completamente díspares, não atende a este novo momento que o Brasil passa a vivenciar" (BAHIA; NUNES, 2015, p. 732).

Ao invés de levar seu voto escrito na sessão de julgamento ${ }^{2}$, o que permite apenas voto de adesão ou rejeição por seus pares, o relator deveria convidar à discussão para a efetiva votação em colegiado, para o pleno debate dos fundamentos e futura definição da ratio decidendi. $\mathrm{Na}$ verdade, não há qualquer racionalidade em decidir antes de deliberar nem, muito menos, em "justificar por escrito antes de decidir. É muito importante perceber a distinção entre decisão colegiada e ajuntamento de decisões individuais dos membros do colegiado" (MARINONI, 2015).

A necessidade de novo procedimento de votação em colegiado para criação de precedentes se dá mesmo nos casos de votação unânime. É comum no Supremo Tribunal Federal, na discussão de casos complexos, que cada ministro apresente seu voto escrito na sessão do julgamento e, finalizada a votação, mesmo que o resultado se dê por decisão unânime, cada voto apresente uma razão de decidir, sem nenhuma deliberação colegiada, o que impede a criação de precedente neste acórdão. Deste procedimento resulta um acórdão composto de um apanhado de votos independentes, contendo o entendimento de cada ministro e não a decisão comum adotada ao caso, demonstrando "a ausência de linearidade 
argumentativa e a diversidade de premissas usadas pelos ministros na formação de suas decisões" (BAHIA; NUNES, 2015, p. 753-754).

O mesmo ocorre nos casos mais simples, em que há leitura do voto do relator e mero acompanhamento pelos demais membros do colegiado, sem deliberação sobre o tema. Este julgamento cria um precedente extremamente fraco, podendo provocar futuro julgamento de caso correlato, sob outro fundamento e com outro direcionamento, pois não há identificação da Corte com o precedente anterior, dada a ausência de deliberação institucional sobre o assunto.

Além de prever um rol de precedentes, o Novo Código de Processo Civil estabelece, em seu art. 926, que os "tribunais devem uniformizar sua jurisprudência e mantê-la estável, íntegra e coerente”, com o intuito de gerar previsibilidade nos julgamentos, de acordo com o entendimento consolidado nos tribunais.

A jurisprudência estável é aquela que não é alterada por entendimento individual do relator, respeitando-se os precedentes definidos por tribunal superior ou pelo próprio tribunal que está a julgar um caso concreto (PANUTTO, 2017, p. 144).

Contudo, apenas a estabilidade não atinge os objetivos traçados pelo sistema de precedentes definido no Novo Código de Processo Civil, pois jurisprudência estável não significa necessariamente um entendimento jurisprudencial que foi consolidado à luz das garantias constitucionais, pois é "possível decidir reiteradamente em um sentido equivocado, injusto, que viole o Direito, e, ainda assim, afirmar que se está dando cumprimento à ideia de estabilidade" (HORTA; NUNES, 2015, p. 323-324).

A coerência garante a aplicação dos mesmos preceitos e princípios que foram aplicados anteriormente, assegurando o respeito ao princípio da isonomia, visando garantir tratamento igualitário a casos similares pelo Poder Judiciário, impedindo, desta forma, a arbitrariedade e discricionariedade pelo juiz, pois não há nenhum ganho democrático em se possuir Constituição e legislação consagradoras de direitos se as questões jurídicas puderem "ser solucionadas em parâmetros discricionários que são necessariamente não jurídicos, isto porque são pautados na vontade e na subjetividade do julgador" (ABBOUD, 2014, p. 462). 
Já a integridade, a qual "é uma virtude ao lado da justiça, da equidade e do devido processo legal” (DWORKIN, 2014, p. 261-262), objetiva garantir aos jurisdicionados o direito, em princípio, de ter seus casos julgados de acordo com a melhor concepção daquilo que as normas jurídicas da comunidade "exigiam ou permitiam na época em que se deram os fatos", pois a "integridade exige que essas normas sejam consideradas coerentes, como se o Estado tivesse uma única voz" (DWORKIN, 2014, p. 262-263), devendo o juiz considerar a concepção moral da sociedade para a melhor solução do conflito.

A prolação de decisões dotadas de integridade cabe a todo juiz, fazendo com que julgue o caso concreto tendo como parâmetro o Direito em conjunto. "Para isto os princípios devem ser reconstruídos no presente, levando-se em conta o passado (de forma reflexiva e não como mera repetição) e também para o futuro, como abertura para as próximas gerações" (BAHIA; NUNES; THEODORO JÚNIOR, 2010, p. 36). ${ }^{3}$

A necessidade de manutenção da jurisprudência estável, íntegra e coerente demonstra que não há apenas razões institucionais para se respeitar precedentes, mas também razões morais, demandando uma reinterpretação do Direito com base na concepção da moralidade política da sociedade, estabelecendo aos tribunais a necessidade de se criar e manter precedentes moralmente justificáveis (BUSTAMANTE, 2012, p. 251-255).

A despeito de as decisões oriundas de controle concentrado e as súmulas vinculantes já terem efeito vinculante por previsão constitucional ${ }^{4}$, o Novo Código de Processo Civil propiciou, em seu art. 926, um ganho institucional para estas decisões ao estabelecer que os precedentes judiciais vinculantes (dentre os quais as decisões de controle concentrado e as súmulas vinculantes se incluem), devem ser dotados de estabilidade, coerência e integridade, fato que acarreta ao Supremo Tribunal Federal, por determinação legal, a obrigatoriedade de respeitar estas diretrizes também quando do exercício desta modalidade de controle de constitucionalidade.

Desta forma, demonstra-se que a plena criação de precedentes, por meio de efetiva deliberação, dotados de estabilidade, integridade e coerência não fica adstrita à vontade política dos tribunais, mas sim decorre de lei, devendo nossas Cortes se adequarem aos dispositivos do 
Novo Código de Processo Civil para garantir maior segurança jurídica à sociedade, sendo certo que o exemplo deve ser dado pelo Supremo Tribunal Federal.

O acórdão proferido pelo Supremo Tribunal Federal na Ação de Descumprimento de Preceito Fundamental no 132, que tratou da constitucionalidade da união homoafetiva, exemplifica este procedimento, no qual cada ministro procurou demonstrar seu entendimento sobre o tema, sem que o tribunal estipulasse a ratio decidendi da decisão. 0 acórdão é composto pela ementa, pelo voto do relator, ministro Ayres Britto, pelo voto da ministra Carmen Lúcia e pelos votos dos ministros Luiz Fux, Ricardo Lewandowski, Joaquim Barbosa, Gilmar Mendes, Marco Aurélio, Celso de Mello e Cezar Peluso ${ }^{5}$, os quais apresentaram diferentes razões de decidir, a despeito de todos terem votado pela procedência do pedido. A unidade do acórdão é notada apenas na ementa, a qual é inútil para futura identificação da ratio decidendi, tanto pela insuficiência de seus fundamentos, quanto pelo fato de seu texto não ser deliberado pela Corte, sendo elaborada monocraticamente pelo ministro relator após a sessão de julgamento e publicada juntamente com o acórdão. ${ }^{6}$

A Ação de Descumprimento de Preceito Fundamental no 130, que tratou da inconstitucionalidade da Lei de Imprensa, também tem acórdão caracterizado pela apresentação de votos em separado, com enorme dificuldade de identificação da ratio decidendi, fato que gerou insegurança jurídica pela falta de certeza das matérias de direito em análise, ainda durante seu julgamento. ${ }^{7}$ Meses depois, no julgamento da Reclamação $9.428,{ }^{8}$ foi provocada a interpretação dos votos de dez dos onze ministros que haviam participado da votação na ADPF 130, a fim de esclarecer a razão de decidir da decisão proferida neste processo (COSTA, 2014, p. 139).

A recente crise institucional entre os Poderes da República causada pelo afastamento em caráter liminar do Presidente do Senado Federal, Renan Calheiros, por decisão monocrática ${ }^{9}$ do ministro Marco Aurélio Melo proferida na medida cautelar nos autos da Ação de Descumprimento de Preceito Fundamental no 402, proposta pelo partido político Rede Sustentabilidade para questionar a possibilidade de "réus em ação penal perante o STF poderem ocupar cargos que estão na linha de substituição 
na Presidência da República", externou a necessidade da estabilização política de nossa Corte Constitucional, a qual deve demonstrar sua força como órgão colegiado e não como um apanhado de ministros autônomos. Imprescindível, neste momento, que o Supremo Tribunal Federal, servindo de modelo para os demais tribunais do país, adquira uma postura de diálogo entre seus membros, para que as decisões proferidas sejam pautadas nos precedentes do tribunal e não com base no entendimento de determinado ministro, ${ }^{10}$ de modo a enfrentar os argumentos apresentados pelo colegiado de forma sincera e fundamentada (LAURENTIIS; PANUTTO, 2016). No âmbito do Supremo, houve mal-estar entre os ministros, pelo fato de uma decisão tão impactante ter sido concedida monocraticamente. Visando a contornar a crise, a ministra Cármen Lúcia, presidente do STF, levou ao plenário referida medida cautelar para referendo da liminar concedida contra Renan Calheiros, a qual foi rejeitada por maioria de votos ${ }^{11}$.

Este procedimento de votação colegiada, pautado pelo argumento de autoridade ${ }^{12}$, em detrimento do debate que pudesse gerar uma verdadeira decisão colegiada, fere o princípio da segurança jurídica, pois a razão de decidir é obtida pelo entendimento do julgador e não pelo entendimento do colegiado. Mudando-se o julgador, muda-se o entendimento. "No caso de argumentações por autoridade, a formação de padrões decisórios se dá a partir das razões subjetivas para decidir" (RODRIGUEZ, 2013, p. 70-80). ${ }^{13}$

A despeito disto, para efetivo respeito ao sistema de precedentes implantado pelo Novo Código de Processo Civil, nos termos de seu art. 927, quando da prolação dos acórdãos aptos a gerar precedentes, o Supremo Tribunal Federal, o Superior Tribunal de Justiça e os Tribunais de segundo grau, além de julgarem o caso concreto, deverão definir no acórdão sua ratio decidendi, para efetivo respeito aos princípios constitucionais da segurança jurídica, da isonomia e da previsibilidade.

O Novo Código de Processo Civil deveria ter avançado visando disciplinar o procedimento de votação em colegiado para obtenção de decisão resultado de plena deliberação pelos tribunais, estabelecendo critérios para definição da ratio decidendi e efetiva criação de precedentes, o que, infelizmente, não ocorreu. 


\section{A BUSCA PELA SEGURANÇA JURÍDICA NA CRIAÇÃO E RES- PEITO AOS PRECEDENTES}

O Novo Código de Processo Civil almeja a segurança jurídica calcada nos fundamentos da decisão para despersonalizar o processo decisório, tornando menos importante a pessoa do juiz. Para superar um fundamento, "será necessário argumentar de maneira racional para convencer os demais juízes do tribunal de sua incorreção para o caso" (RODRIGUEZ, 2013, p. 107-111).

Entretanto, não haverá avanço jurisdicional no estabelecimento pelo Novo Código de Processo Civil, em seu art. 927, de um rol de precedentes que vincularão o próprio tribunal gerador, bem como as instâncias inferiores, se as decisões que tipificarem tal dispositivo não forem aptas a gerar precedentes, sendo de difícil ou incerta aplicação futura, pela impossibilidade de identificação da razão de decidir no julgado, confundindo-se os fundamentos da decisão com seu obter dicta que "não são centrais para a linha de raciocínio defendida pelo tribunal ou pelo julgador" (ARGUELHES; RIBEIRO, 2015), o que prejudica o respeito aos precedentes judiciais vinculantes ora inseridos em nosso sistema jurídico.

O que o Novo Código de Processo Civil almeja, para além da criação dos precedentes judiciais vinculantes, é a garantia da igualdade e previsibilidade, para que casos futuros possam ser julgados com base em precedentes com a mesma matéria de direito, garantindo assim maior segurança às relações jurídicas e isonomia nas soluções de conflito, com respeito à máxima treat like cases alike.

Não se pode mais conceber a plena autonomia na interpretação de matéria de direito pelo julgador quando da prolação da decisão, desconsiderando os precedentes de seu próprio tribunal e das instâncias superiores. 0 juiz deve "manter a coerência e zelar pela respeitabilidade e pela credibilidade do Poder Judiciário. Além disto, não deve transformar a sua própria decisão, aos olhos do jurisdicionado, em um 'nada'" (MARINONI, 2009 , p. 207), forçando a parte derrotada a interpor recurso para fazer valer o entendimento da matéria de direito já definida em precedente (PANUTTO, 2017, p. 65). 
A solução diversa para casos correlatos, além de gerar insegurança jurídica, desrespeita o princípio da igualdade, pois, como as normas devem ser aplicadas de maneira uniforme e impessoal, os cidadãos que se encontram em situação equivalente devem receber igual tratamento (ÁVILA, 2012, p. 229-230).

Para que possam cumprir esta determinação legal, o que fará com que a própria Corte geradora do precedente, além das instâncias inferiores, a Administração Pública, os advogados, defensores públicos, Ministério Público e sociedade em geral possam respeitá-lo, imprescindível que nossos tribunais internalizem a necessidade de plena deliberação e revejam o procedimento para votação em colegiado para a criação de precedentes.

Diante disto, o Poder Judiciário brasileiro deverá se ater à sua função institucional de pautar suas decisões para solução de casos futuros, de modo a facilitar a solução de conflitos objeto de processos judiciais por meio da aplicação dos precedentes judiciais vinculantes, pois o “Judiciário não se presta exclusivamente para decidir conflitos concretos, mas ainda deve cuidar para que as suas decisões possam servir de orientação para casos futuros" (TUCCI, 2004, p. 12-25), bem como para prevenir o surgimento de novos processos judiciais, pois a sociedade saberá, de antemão, os precedentes dos tribunais, o que possibilitará a definição prévia de formas de conduta e a consequente prevenção e solução extrajudicial de conflitos de interesses (PANUTTO, 2017, p. 73).

\section{A EXPERIÊNCIA DELIBERATIVA DE OUTRAS CORTES CONSTITUCIONAIS EM DIVERSOS TIPOS DE DECISÃO CO- LEGIADA}

Os problemas apontados anteriormente na forma de deliberação colegiada não são exclusivos do Brasil. Mesmo os países com maior tradição na criação de precedentes se preocupam constantemente em ajustar o procedimento deliberativo de suas Cortes Constitucionais para garantir que a resposta dada seja efetivamente deliberada.

Pode-se dizer que há três tipos de decisão colegiada: seriatim, per curiam e majoritarian practice, as quais, com pequenas variações, são utilizadas em tradicionais Cortes Constitucionais. 


\section{DECISÃO SERIATIM}

A decisão seriatim é caracterizada pela apresentação em série dos votos dos integrantes de um colegiado, resultando o acórdão da somatória destes votos, sem interação entre si, privilegiando-se a exposição da opinião de cada julgador, em detrimento do entendimento institucional sobre o tema. 0 acórdão é uma colcha de retalhos ${ }^{14}$, sem preocupação com a construção colegiada da decisão, com apresentação do voto individualmente por cada julgador, na intenção de que seu entendimento prevaleça perante os demais membros do colegiado.

A unidade da decisão é garantida, muitas vezes, apenas pelo dispositivo, podendo haver diferentes fundamentos de matéria de direito em cada voto apresentado. Somados os votos que são favoráveis e os que são contrários, chega-se ao resultado da decisão, sem considerar a diversidade de fundamentos apresentada.

Na narrativa do segundo capítulo demonstrou-se que a prática deliberativa no Supremo Tribunal Federal, sobretudo nos casos complexos, é a seriatim, resultando num acórdão formado pelo apanhado dos votos do ministro relator e dos demais ministros, os quais se sentem compelidos, seja pela tradição, seja pela transmissão televisiva das sessões de julgamento, a apresentar sua própria "decisão" ao caso, desconsiderando os votos dos demais ministros. Resulta-se disto, mesmo que os votos tenham o mesmo dispositivo, num acórdão sem uma identidade deliberativa da Corte, o que impede a criação de precedente desta decisão, pois não há ratio decidendi como resultado de deliberação colegiada.

A experiência no Supremo Tribunal Federal leva a crer que, nos julgamentos dos casos complexos, cada ministro se preocupa em externar sua opinião para os demais ministros e também, e sobretudo, para a comunidade externa. É raro, nestes casos, haver interação entre os ministros para que o voto de um contribua com os votos dos demais. Aliás isto se torna extremamente difícil, na medida em que os votos já são levados prontos para a sessão de julgamento, de modo que a sessão colegiada se resume a mera leitura dos entendimentos individuais.

A determinação legal de criação e respeito aos precedentes judiciais vinculantes, nas hipóteses do art. 927 do NCPC, cabe a todos os tribunais, 
mas é inegável a responsabilidade do Supremo Tribunal Federal na incorporação deste novo sistema jurídico-processual, para que demonstre internamente, nas sessões de julgamento, e para a comunidade jurídica e sociedade em geral, que reconhece sua função na plena deliberação colegiada para que as decisões resultem em entendimento institucional. ${ }^{15}$

A tradicional House of Lords da Inglaterra também adota a decisão seriatim, característica que gera críticas da doutrina especializada ${ }^{16}$, pela mesma razão de difícil aplicação futura do precedente.

A grande distinção entre o stare decisis inglês e o sistema de precedentes implementado pelo Novo Código de Processo Civil Brasileiro, é que, na Inglaterra, as decisões não nascem como precedentes, sendo proferidas e futuramente podendo ser invocadas como tal. No Brasil, se a decisão proferida tipifica uma das hipóteses do art. 927 do NCPC, ela já nasce como precedente. Desta forma, a adoção da decisão seriatim na Inglaterra dificulta a futura aplicação da decisão como precedente, pela dificuldade de se identificar sua ratio decidendi; no Brasil, este modelo de decisão gera dificuldade tanto na criação (vez que a decisão já nasce como precedente, por disposição legal), como na sua futura aplicação.

A definição da ratio decidendi nos países de common law nem sempre se dá quando do julgamento do caso concreto. Na medida em que o julgado de um caso anterior passa a ser aplicado para solução de casos similares futuros, o juiz identifica a ratio decidendi e aplica o entendimento anterior como precedente. Portanto, a criação do precedente, nestes casos, surge não pelo órgão prolator da decisão originária, mas pelo juiz que aplica decisão anterior para solução de caso análogo futuro. ${ }^{17}$

Por esta razão, para melhor aplicabilidade futura do precedente, tem-se defendido, no sistema inglês, a existência de um único fundamento nas decisões, como forma de melhor identificação da razão de decidir. ${ }^{18}$

Por força da tradição inglesa, a Suprema Corte norte-americana, inicialmente, também adotou a decisão seriatim, em modelo próximo ao adotado atualmente pelo Supremo Tribunal Federal em casos complexos. Neste modelo, que funcionou entre 1793 e 1800, a Suprema Corte norte-americana anunciava suas decisões através das seriatim opinions, de modo que "cada Justice pronunciava seu voto individualmente e o conjunto de todas as opiniões expostas 'em série' era assim apresentado ao público” (VALE, 2014). 


\section{DECISÃO PER CURIAM}

A decisão per curiam caracteriza-se pela apresentação institucional dos resultados da deliberação. A decisão não é dos julgadores, em votação unânime ou por maioria de votos, mas sim do colegiado. É a Corte que, decidindo em conjunto, anuncia o resultado da votação, despersonificando a figura dos julgadores e fortalecendo a figura da instituição. "Deste modo, provoca-se a impressão que o Tribunal tem voz própria, que não se identifica necessariamente com a dos ministros que o compõem" (RUIZ, 2000, p. 156, tradução nossa).

Para ser possível a decisão per curiam, a Corte deve chegar a um consenso inicialmente sobre os fundamentos e, posteriormente, sobre o dispositivo. Não há necessidade de que o consenso seja unânime, podendo a decisão ser proclamada por maioria. Os fundamentos são apresentados, inicialmente, por um juiz relator, para posterior debate visando o consenso. Este sistema é adotado pela Corte de Cassação Francesa (KORNHAUSER, 2015).

Este modelo de decisão demonstra um desafio para os casos complexos, pela dificuldade de se chegar a um consenso diante de uma variedade de fundamentos e dispositivos, com entendimentos muito distantes entre si. Nestes casos, a deliberação pode se prolongar, sem grandes perspectivas, sobretudo pelo fato deste modelo de decisão não contemplar os votos divergentes (RUIZ, 2000).

Pelo narrado, a decisão per curiam se demonstra antagônica à decisão seriatim. Se esta não tem sido útil ao fortalecimento institucional de nosso Supremo Tribunal Federal, a adoção irrestrita daquela em nosso sistema seria trágico, pois, pela tradição de nossa Corte Constitucional de apresentação de votos individuais pelos ministros, seria improvável um entendimento institucional com ausência de registro de votos divergentes, pois "sólo una visión ingenua y, si se permite la expresión [...] de la decisión judicial, permite conformarse com la regla de la absoluta prohibición de la expresión del disenso en órganos judiciales colegiados" (RUIZ, 2000, p. 169).

Mesmo que se melhore o procedimento de votação colegiada no Supremo Tribunal Federal, para garantia de maior deliberação, com vistas 
ao consenso entre os ministros, seria inconcebível, a desconsideração do voto divergente. Aprimorando-se o procedimento deliberativo ${ }^{19}$ no Supremo Tribunal Federal seria possível a eliminação dos votos meramente concorrentes, os quais concordam com o dispositivo apontado pelo relator, mas discordam parcial ou totalmente dos fundamentos apresentados. 0 voto divergente, mesmo que vencido, seria importante permanecer em nosso sistema, pois aprimora o processo democrático, garante a riqueza de ideias e pode acenar futura alteração do precedente. De toda forma, teria que ser garantida uma decisão que, mesmo com voto vencido, resulte em entendimento institucional, tornando o Supremo Tribunal Federal em "uma instituição que tenha voz própria, que não seja a soma de 11 vozes dissociadas" (SILVA, 2012, p. 197-227).

\section{MAJORITARIAN PRACTICE}

Buscando o meio termo entre as decisões seriatim e per curiam, a decisão resultante da majoritarian practice, adotada pela Suprema Corte norte-americana, segue inicialmente o rito da decisão seriatim, com a colheita dos votos individuais dos julgadores. Atingida a maioria, a Corte segue na deliberação para definição da ratio decidendi contendo o entendimento institucional acerca dos fundamentos e do dispositivo da decisão. A redação do entendimento da Corte cabe ao julgador mais velho entre aqueles que ficaram na maioria (KORNHAUSER, 2015).

Este modelo de decisão se diferencia da decisão per curiam pois são considerados os entendimentos minoritários, cujos votos em separado são agregados à decisão resultado da opinião da Corte (KORNHAUSER, 2015). "Como punto de partida, el tribunal aspira al acuerdo y, en la medida de lo posible, a la unanimidad, pero ninguna regla [...] limita el derecho del juez a expresar su opinión aparte” (RUIZ, 2000, p. 159).

A Suprema Corte norte-americana, que, como já dito, originalmente adotou a decisão seriatim por influência inglesa, passou a adotar, "a partir de 1801", a majoritarian practice, fato que se demonstrou "crucial para a afirmação da Suprema Corte como unidade institucional em face dos demais Poderes" (VALE, 2014). 
Este modelo aparenta ser adequado ao Supremo Tribunal Federal e aos demais tribunais de nosso país, pois preserva de certa maneira a tradição de apresentação dos votos individuais em série, mas busca, ao final, o entendimento institucional sobre a matéria de direito decidida. Ademais, contempla também nossa tradição de respeitar os votos vencidos, agregando-os em separado à decisão que contém a opinião da Corte sobre o tema. Assim, a majoritarian practice demonstra ser a que mais respeita a tradição brasileira de votação colegiada e, se adotada por nossos tribunais, atenderá às determinações do Novo Código de Processo Civil no tocante a criação e respeito aos precedentes, de modo a pautar a solução de conflitos similares futuros, com uma decisão que contemple não apenas o entendimento institucional sobre tema, mas também os votos dissidentes, como forma de oxigenação do precedente.

Haveria necessidade de outras modificações procedimentais, tal como a apresentação prévia do voto do relator, para possibilitar conhecimento dos demais membros do colegiado acerca do assunto e viabilizar a deliberação, pois "não parece fazer sentido que os ministros cheguem no momento de decidir sem saber a opinião daquele que mais intensamente se ocupou do caso a ser decidido" (SILVA, 2015). Ademais, cabe ao relator $^{20}$ a importância de definir a matéria de direito em seu voto, o qual, na maioria das vezes, será seguido pelo colegiado, reforçando a necessidade de revisão procedimental nos casos em que há acompanhamento do voto do relator, sem apresentação de voto pelos demais ministros, de modo a legitimar institucionalmente este precedente.

Certamente estas alterações procedimentais demandarão grande discussão interna no Supremo Tribunal Federal, com respectiva adequação de seu regimento interno, o que deverá contar com prévias diretrizes fixadas pelo Conselho Nacional de Justiça, para balizar o tema não somente no Supremo, mas em todos os tribunais do país.

\section{CONCLUSÃO}

A implantação dos precedentes judiciais vinculantes demandará conscientização dos membros de nossos tribunais acerca de sua importância no sistema judiciário, para além de sua individual importância 
como julgador, pois o precedente nasce do entendimento deliberado da Corte e não do entendimento individual de cada julgador.

O exemplo do que necessita de ajustes e o laboratório para a correção de vicissitudes é o Supremo Tribunal Federal. Fica claro em nossa Corte Constitucional que, em regra, cada ministro se vê tão importante como o próprio tribunal que integra. Não há entendimento plenamente deliberado. Há liminares relevantes concedidas monocraticamente, muitas vezes sem lastro ou até contrárias a precedentes da Corte. Nas decisões colegiadas, nos casos mais simples, há mero acompanhamento do voto do relator, sem deliberação; mudando-se o relator, muda-se o entendimento. Nos casos mais complexos cada ministro faz prevalecer seu próprio entendimento sobre o tema, resultando num acórdão composto de votos com enorme variedade de fundamentos, havendo unidade muitas vezes apenas no dispositivo e na ementa.

Como fomentar a cultura de precedentes, agora legalmente previstos no Novo Código de Processo Civil, se nossa mais alta Corte não reconhece a importância na deliberação colegiada?

Esta situação acarreta a necessidade de imediata conscientização do Supremo Tribunal Federal para atuar efetivamente como órgão colegiado, pois a força de nossa Corte Constitucional está em sua colegialidade e não em seus ministros individualmente. Cada liminar concedida em casos de relevância nacional, cada entrevista concedida por ministros abordando temas em pauta, cada acórdão composto de um apanhado de votos díspares, leva à fraqueza institucional de nossa Corte Constitucional.

Imprescindível o papel do Supremo Tribunal Federal na criação e respeito de seus próprios precedentes, pois atua como norte aos demais tribunais do país e aos juízes, de uma maneira geral.

Entretanto, esta conscientização pode não nascer naturalmente, pois leva à perda de poder individual de cada ministro. Necessário, então, que o Conselho Nacional de Justiça paute esta discussão para estabelecer parâmetros para a deliberação colegiada em busca da plena criação de precedentes. Estes parâmetros deverão ter como base a majoritarian practice, mais próxima da realidade brasileira de respeito dos votos em série e dos votos divergentes, mas com acórdão resultante de entendimento institucional. 


\section{Disto dependerá a plena eficácia do sistema de precedentes judiciais vinculantes estabelecido pelo Novo Código de Processo Civil.}

\section{NOTAS}

1 Art. 927: Os juízes e os tribunais observarão: I - as decisões do Supremo Tribunal Federal em controle concentrado de constitucionalidade; II - os enunciados de súmula vinculante; III - os acórdãos em incidente de assunção de competência ou de resolução de demandas repetitivas e em julgamento de recursos extraordinário e especial repetitivos; IV - os enunciados das súmulas do Supremo Tribunal Federal em matéria constitucional e do Superior Tribunal de Justiça em matéria infraconstitucional; $\mathrm{V}$ - a orientação do plenário ou do órgão especial aos quais estiverem vinculados [...].

2 “O fato de que os votos já chegam prontos e são, com muita frequência, meramente lidos na sessão pública, dá alguma medida do descaso relativo à opinião dos outros membros. Parece evidente não haver consciência do valor da convergência de posições individuais quando não se faz sequer um esforço de composição de votos que alcançam um mesmo ponto de chegada, apesar de percorrerem caminhos diversos." MENDES, Conrado Hübner. Desempenho deliberativo de cortes constitucionais e o STF. In: Ronaldo Porto Macedo; Catarina Barbieri (Org.). Direito e Interpretação: Racionalidade e Instituições. São Paulo: Saraiva, 2011. p. 357.

3 "Na especificidade, Dworkin, ao combinar princípios jurídicos com objetivos políticos, coloca à disposição dos juristas/intérpretes um manancial de possibilidades para a construção/elaboração de respostas coerentes com o direito positivo - o que confere uma blindagem contra discricionariedades (se assim se quiser, pode-se chamar a isso de 'segurança jurídica') - e com a grande preocupação contemporânea do Direito: a pretensão de legitimidade. (...) Fundamentalmente - e nesse sentido não importa qual seja o sistema jurídico em discussão -, trata-se de superar as teses convencionalistas e pragmatistas a partir da obrigação de os juízes respeitarem a integridade do Direito e a aplicá-lo coerentemente. Numa palavra: a resposta correta (adequada à Constituição e não à consciência do intérprete) tem um grau de abrangência que evita decisões ad hoc. Entenda-se, aqui, a importância das decisões em sede de jurisdição constitucional, pelo seu papel de proporcionar a aplicação em casos similares. Haverá coerência se os mesmos princípios que foram aplicados nas decisões forem aplicados para os outros casos idênticos; mas, mais do que isso, estará assegurada a integridade do Direito a partir da força normativa da Constituição." STRECK, Lenio Luiz. 0 que é isto: decido conforme minha consciência? 5. ed. Porto Alegre: Livraria do Advogado, 2015. p. 116-117.

4 Art. 102, § 2o e art. 103-A, caput, da Constituição Federal, ambos com redação pela Emenda Constitucional no 45 .

5 Ausente a ministra Ellen Gracie e impedido o ministro Dias Toffoli.

6 Disponível em http://redir.stf.jus.br/paginadorpub/paginador.jsp?docTP=AC\&docID=628633. Acesso em 30/01/17.

7 Thales Morais da Costa faz profunda análise do julgamento da ADPF 130, bem como de reclamações posteriores propostas com fundamento nesta ADPF, trazendo o debate entre os ministros e externando a grave divergência quanto à ratio decidendi. In COSTA, Thales Morais da. Conteúdo e alcance da decisão do STF sobre a Lei de Imprensa na ADPF 130. Revista Direito GV, jan-jun 2014, p. 119-154.

8 Reclamação proposta pelo Jornal 0 Estado de São Paulo contra decisão judicial que vedou veiculação de matéria jornalística objeto de processo judicial em trâmite com segredo de justiça, sob o argumento de violação da autoridade da decisão proferida na ADPF 130. Esta reclamação não foi conhecida sob o entendimento de ausência de violação à autoridade da decisão proferida na ADPF 130. Acórdão disponível em http://redir.stf.jus.br/paginadorpub/paginador. jsp?docTP=AC\&docID=612474. Acesso em 06/02/2017. 
9 Disponível em http://www.stf.jus.br/arquivo/cms/noticiaNoticiaStf/anexo/ADPF402.pdf. Acesso em 16/01/2017.

10 "Nesse caso, suas preferências acabam prevalecendo em detrimento das preferências que resultariam da agregação das decisões dos ministros de todo o tribunal colegiado (observar que se fosse decisão monocrática a informalidade não é necessária). Esses comportamentos informais produzem um efeito: cada ministro pode se constituir em uma espécie de instituição para atores externos ao tribunal, na medida em que suas preferências prevalecem e devem ser levadas em consideração por tais atores." ARGUELHES, Diego Werneck; RIBEIRO, Leandro Molhano. 0 Supremo Individual: mecanismos de atuação direta dos Ministros sobre o processo político. In: Direito, Estado e Sociedade. n.46. p. 121 a 155. jan/jun 2015.

11 Votaram pela revogação da medida liminar, mantendo Renan Calheiros no cargo, os ministros Celso de Mello, Dias Toffoli, Teori Zavascki, Luiz Fux, Ricardo Lewandowski e a ministra Cármen Lúcia.

12 "O individualismo predominante no STF, porém, não tem muito a ver com "ganhar o debate". Ganhar ou perder, no ambiente do Tribunal, importam menos que marcar publicamente a opinião individual, especialmente nos casos de maior saliência pública. O STF cultiva e premia a emissão de "opiniões fortes", que resistem, por princípio, ao contra-argumento para evitar qualquer sinal de fraqueza moral e intelectual." MENDES, Conrado Hübner. O projeto de uma corte deliberativa. In: Adriana Vojvodic; Henrique Motta Pinto; Paula Gorzoni; Rodrigo Pagani de Souza (Org.). Jurisdição Constitucional no Brasil. São Paulo: Malheiros, 2012. p. 72-73.

13 Virgílio Afonso da Silva aponta elementos importantes para a efetiva deliberação em colegiado: "Collegiality implies, among other things, (i) the disposition to work as a team; (ii) the absence of hierarchy among the judges (at least in the sense that the arguments of any and all judges have the same value); (iii) the willingness to listen to arguments advanced by other judges (i.e. being open to being convinced by good arguments of other judges); (iv) a cooperativeness in the decision-making process; (v) mutual respect among judges; (vi) the disposition to speak, whenever possible, not as a sum of individuals but as an institution (consensus seeking deliberation)." SILVA, Virgílio Afonso da. Deciding without deliberation. International Journal of Constitutional Law, v. 11, no 3, 2013. p. 557-584.

14 "Uma seriatim não deliberativa, nessa perspectiva, assemelha-se a uma colha de retalhos - decisões individuais coladas lado a lado, que não conversam entre si." MENDES, Conrado Hübner. 0 projeto de uma corte deliberativa. In: Adriana Vojvodic; Henrique Motta Pinto; Paula Gorzoni; Rodrigo Pagani de Souza (Org.). Jurisdição Constitucional no Brasil. São Paulo: Malheiros, 2012. p. 67.

15 "Se os tribunais superiores querem assumir uma função nova - e parece que necessitam urgentemente - eles precisam assumir também a sua parcela de responsabilidade, mudando a forma de julgar os casos que lhes são submetidos. Os votos que compõem um julgamento colegiado não podem ter fundamentos dispersos, não bastando que o dispositivo seja uníssono porque a ratio decidendi de um precedente não está no dispositivo da decisão, que é vinculante apenas para as partes do caso concreto. Se o tribunal não tem preocupação com a ratio decidendi ele não pode esperar que o precedente seja respeitado futuramente, porque ele contribuiu ou criou essa situação de dificuldade da interpretação do precedente." NOGUEIRA, Gustavo Santana. Precedentes Vinculantes no Direito Comparado e Brasileiro. Salvador: Juspodivm, 2013. p. 240-241.

16 "When each judge pursues an individual decision-making protocol, individual protocol, each express the reasons for her disposition that she would give if she were sitting alone. Under this practice, however, the reasons of the court remain unclear. The obscurity derives from the multiplicity of rules (and reasons for rules) that the panel of judges may announce. Though the choice of disposition is dichotomous, the choice among rules is not. In general, one can support a given disposition with many different rules." KORNHAUSER, Lewis A. Deciding Together. Revista de Estudos Institucionais. Vol. 1, 1, 2015, p. 51. Disponível em https://www.estudosinstitucionais. com/REI/article/view/10. Acesso em 28/01/2017.

17 "La determinación de lo que vale por fundamento (rationale) de la decisión del tribunal, uma tarea que han de llevar a cabo los jueces vinculados por el holding de la decisión, és ocasional- 
mente uma pesquisa complicada, para la que, de modo nada sorprendente, sirve como pauta de orientación la regla de identificar como ratio de la decisión el mínimo común compartido por los argumentos individuales. Por esta razón, algunos autores distinguen entre la ratio decidendi del juez, digamos, el principio de derecho conforme al cual dispuso el caso y que pretendió fijar como precedente, y la efectiva "regla de caso", la que jueces posteriores deducen como precedente vinculante a partir de su interpretación del caso. Si aun esse "mínimo común" parece ausente, el precedente que la decisión fija quedará reducito a la conexión entre los hechos relevantes del litigio (material facts) y el resultado final." RUIZ, Maria Angeles Ahumada. La regla de la mayoría y la formulación de doctrina constitucional. Rationes decidendi em la STC 136/1999. Revista Española de Derecho Constitucional. Año 20. Núm. 58. Enero-Abril 2000, p. 157.

18 "Uno de los câmbios que consideramos sería benéfico para el Derecho inglés sería que se incrementara el número de asuntos em los cuales el tribunal competente para resolver las apelaciones está obligado a que su sentencia este integrada no por múltiples votos razonados, sino por una sola ponencia. $(. .)<.<$ Consideramos que es una importante ventaja para quienes están encargados de administrar justicia en el área del Derecho penal, así como para aquellos jueces que están obligados a seguir las decisiones del Tribunal de Apelaciones Criminales, es que tal tribunal debe exponer su decisión en una única ponencia en la que presente el Derecho relevante, con lo cual es innecesario entrar a examinar múltiples votos cuál fue el fundamento de la decisión que es común a todos ellos>>. Sin lugar a dudas hay quienes consideran que ello es igualmente cierto en relación con la administración de la justicia en matéria civil." CROSS, Rupert; HARRIS, J. W. El Precedente en el Derecho Inglés. Tradução de Maria Angélia Pulido. Barcelona: Marcial Pons, 2012. p. 120.

19 "Além da falta de conversa prévia, os ministros também reconhecem que a redação dos votos em momento anterior ao debate não somente prejudica a deliberação como também é responsável pelo elevado número de votos divergentes (e concorrentes)." SILVA, Virgílio Afonso da. De quem divergem os divergentes: os votos vencidos no Supremo Tribunal Federal. In: Direito, Estado e Sociedade. n.47. p. 205 a 255. jul/dez 2015.

20 “Apurou-se que em 242 acórdãos as manifestações sem declarações de voto e o voto do relator já seriam suficientes para formar a maioria. Ao contrário, apenas em 25 acórdãos isso não ocorreu. Isso significa que 9 de cada 10 acórdãos da amostra pesquisada foram fundamentados a partir das razões apresentadas pelo ministro-relator. Detectou-se, assim, que o relator tem, na maioria das vezes, a importante função de fixar a decisão e sua respectiva fundamentação. Com isso, ele desempenha papel de significativa influência no julgamento. Seu voto condutor passa a ser o entendimento do Tribunal, como se pôde observar." SUNDFELD, Carlos Ari; SOUZA, Rodrigo Pagani de. Accountability e Jurisprudência do STF: Estudo Empírico de Variáveis Institucionais e Estrutura das Decisões. In: Adriana Vojvodic; Henrique Motta Pinto; Paula Gorzoni; Rodrigo Pagani de Souza (Org.). Jurisdição Constitucional no Brasil. São Paulo: Malheiros, 2012.

\section{REFERÊNCIAS}

ABBOUD, Georges. Discricionariedade administrativa e judicial: o ato administrativo e a decisão judicial. São Paulo: Revista dos Tribunais, 2014.

ARGUELHES, Diego Werneck; RIBEIRO, Leandro Molhano. O Supremo Individual: mecanismos de atuação direta dos Ministros sobre o processo político. In: Direito, Estado e Sociedade. n. 46 p. 121 a 155. Jan./jun. 2015.

ÁVILA, Humberto. Segurança jurídica: entre permanência, mudança e realização no direito tributário. São Paulo: Malheiros Editores, 2012. 
BAHIA, Alexandre Gustavo Melo Franco; NUNES, Dierle. Precedentes no CPC2015: por uma compreensão constitucionalmente adequada do seu uso no Brasil. In: BARROS, Lucas Buril de Macedo; FREIRE, Alexandre; PEIXOTO, Ravi. Coletânea Novo CPC: doutrina selecionada. Salvador: Juspodivm, 2015.

BAHIA, Alexandre Gustavo Melo Franco; NUNES, Dierle; THEODORO JÚNIOR, Humberto. Breves Considerações sobre a Politização do Poder Judiciário e sobre o Panorama de Aplicação no Direito Brasileiro: análise da convergência entre o civil law e common law e dos problemas de padronização decisória. Revista de Processo, São Paulo, v. 189, p. 9-52, nov. 2010.

BUSTAMANTE, Thomas da Rosa de. Teoria do precedente judicial. São Paulo: Noeses, 2012.

COSTA, Thales Morais da. Conteúdo e alcance da decisão do STF sobre a Lei de Imprensa na ADPF 130. Revista Direito GV, São Paulo, p. 119-154, jan./jun. 2014.

CROSS, Rupert; HARRIS, J. W. El precedente en el derecho inglés. Tradução de Maria Angélia Pulido. Barcelona: Marcial Pons, 2012.

DWORKIN, Ronald. 0 império do direito. São Paulo: Martins Fontes, 2014.

HORTA, André Frederico; NUNES, Dierle. Aplicação de Precedentes e Distinguishing no CPC/2015: uma breve introdução. In: ATAÍDE JÚNIOR, Jaldemiro Rodrigues de; CUNHA, Leonardo Carneiro da; DIDIER JÚNIOR, Fredie; MACÊDO, Lucas Buril de (Coord.). Precedentes. Coleção Grandes Temas do Novo CPC. Salvador: Juspodivm, 2015.

KORNHAUSER, Lewis A. Deciding together. Revista de Estudos Institucionais, Rio de Janeiro, v. 1, n. 1, 2015. Disponível em https://www.estudosinstitucionais. com REI// article/view/10. Acesso em 28/01/2017.

LAURENTIIS, Lucas Catib De; PANUTTO, Peter. A força do Supremo Tribunal Federal está na colegialidade plena. Consultor Jurídico. Disponível em http://www. conjur.com.br/2016-dez-10/forca-supremo-tribunal-federal-colegialidadeplena. Acesso em: 16 jan. 2017.

MARINONI, Luiz Guilherme. Aproximação Crítica Entre as Jurisdições de Civil Law e Common Law e a Necessidade de Respeito aos Precedentes no Brasil. Revista de Processo, São Paulo, v. 172, p. 175-232, jun. 2009. 
A função das Cortes Supremas e o novo CPC. Consultor Jurídico, São Paulo, 25 maio 2015. Disponível em: http://www.conjur.com.br/2015-mai-25/ direito-civil-atual-funcao-cortes-supremas-cpc. Acesso em: 22 jan. 2016.

MENDES, Conrado Hübner. Desempenho deliberativo de cortes constitucionais e o STF. In: MACEDO, Ronaldo Porto; BARBIERI, Catarina (Org.). Direito e Interpretação: Racionalidade e Instituições. São Paulo: Saraiva, 2011.

. 0 projeto de uma corte deliberativa. In: VOJVODIC Adriana etl al. (Org.). Jurisdição constitucional no Brasil. São Paulo: Malheiros, 2012.

NOGUEIRA, Gustavo Santana. Precedentes vinculantes no direito comparado e brasileiro. Salvador: Juspodivm, 2013.

PANUTTO, Peter. Precedentes judiciais vinculantes: o sistema jurídicoprocessual brasileiro antes e depois do código de processo civil de 2015 (Lei no 13.105, de 16 de março de 2015). Florianópolis: Empório do Direito, 2017.

RODRIGUEZ, José Rodrigo. Como decidem as Cortes?: para uma crítica do Direito (brasileiro). Rio de Janeiro: FGV, 2013.

RUIZ, Maria Angeles Ahumada. La regla de la mayoría y la formulación de doctrina constitucional. Rationes decidendi em la STC 136/1999. Rationes decidendi em la STC 136/1999. Revista Española de Derecho Constitucional. n. 58, enero/ abril, 2000.

SANTOS, Evaristo Aragão. Em Torno do Conceito e da Formação do Precedente Judicial. In: WAMBIER, Teresa Arruda Alvim (Coord.). Direito Jurisprudencial. São Paulo: Revista dos Tribunais, 2012.

SILVA, Virgílio Afonso da. O STF e o controle de constitucionalidade: deliberação, diálogo e razão pública. Revista de Direito Administrativo, Rio de Janeiro, v. 250, p. 197-227, ago. 2012. Disponível em: <http://bibliotecadigital.fgv.br/ojs/ index.php/rda/article/view/4144>. Acesso em: 27 Jan. 2017. doi:http://dx.doi. org/10.12660/rda.v250.2009.4144.

. Deciding without deliberation. International Journal of Constitutional Law, v. 11, no 3, 2013. 
"Um voto qualquer"? 0 papel do ministro relator. Revista Estudos Institucionais. V. 1, 1, 2015.

De quem divergem os divergentes: os votos vencidos no Supremo Tribunal Federal. Direito, Estado e Sociedade, n.47. p. 205-255. jul./dez. 2015.

SUNDFELD, Carlos Ari; SOUZA, Rodrigo Pagani de. Accountability e Jurisprudência do STF: Estudo Empírico de Variáveis Institucionais e Estrutura das Decisões. In: VOJVODIC, Adriana et al. (Org.). Jurisdição constitucional no Brasil. São Paulo: Malheiros, 2012.

STRECK, Lenio Luiz. 0 que é isto: decido conforme minha consciência? 5. ed. Porto Alegre: Livraria do Advogado, 2015.

TUCCI, José Rogério Cruz e. Precedente judicial como fonte do direito. São Paulo: Revista dos Tribunais, 2004.

VALE, André Rufino do. É preciso repensar a deliberação no Supremo Tribunal Federal. Consultor Jurídico, São Paulo, 2014. Disponível em: <http://www. conjur.com.br/2014-fev-01/observatorio-constitucional-preciso-repensardeliberacao-stf>. Acesso em: 28 jan. 2017.

Recebido em: 29-4-2017

Aprovado em: 20-12-2017

\section{Peter Panutto}

Doutor em Direito pela Instituição Toledo de Ensino (2015); mestre em Direito Processual Civil pela Pontifícia Universidade Católica de Campinas; mestre em Direito pela Instituição Toledo de Ensino; professor de Direito Processual Civil, Direito Constitucional, Direito Eleitoral e professor doutor pesquisador da Faculdade de Direito da Pontifícia Universidade Católica de Campinas; advogado. E-mail: ppanutto@hotmail.com

Pontifícia Universidade Católica de Campinas, Centro de Ciências Humanas e Sociais Aplicadas, Faculdade de Direito. Pontifícia Universidade Católica de Campinas (PUCC - Dom Pedro I)

Parque das Universidades, 13086900 - Campinas, SP - Brasil. 